\title{
Neuroprotective Effect of Paeonol Mediates Anti-Inflammation via Suppressing Toll-Like Receptor 2 and Toll-Like Receptor 4 Signaling Pathways in Cerebral Ischemia-Reperfusion Injured Rats
}

\author{
Wen-Yen Liao, ${ }^{1}$ Tung-Hu Tsai, ${ }^{2}$ Tin-Yun Ho, ${ }^{1}$ Yi-Wen Lin, ${ }^{3}$ \\ Chin-Yi Cheng, ${ }^{4}$ and Ching-Liang Hsieh ${ }^{5,6,7,8}$ \\ ${ }^{1}$ Graduate Institute of Chinese Medicine, College of Chinese Medicine, China Medical University, Taichung 40402, Taiwan \\ ${ }^{2}$ Institute of Traditional Medicine, School of Medicine, National Yang-Ming University, Taipei 11221, Taiwan \\ ${ }^{3}$ School of Post-Baccalaureate Chinese Medicine, College of Chinese Medicine, Taichung 40402, Taiwan \\ ${ }^{4}$ School of Chinese Medicine, College of Chinese Medicine, China Medical University, Taichung 40402, Taiwan \\ ${ }^{5}$ Graduate Institute of Acupuncture Science, College of Chinese Medicine, China Medical University, Taichung 40402, Taiwan \\ ${ }^{6}$ Graduate Institute of Integrated Medicine, College of Chinese Medicine, China Medical University, Taichung 40402, Taiwan \\ ${ }^{7}$ Department of Chinese Medicine, China Medical University Hospital, Taichung 40447, Taiwan \\ ${ }^{8}$ Research Center for Chinese Medicine and Acupuncture, China Medical University, Taichung 40402, Taiwan
}

Correspondence should be addressed to Ching-Liang Hsieh; clhsieh@mail.cmuh.org.tw

Received 4 August 2016; Revised 18 November 2016; Accepted 29 November 2016

Academic Editor: Olumayokun A. Olajide

Copyright (C) 2016 Wen-Yen Liao et al. This is an open access article distributed under the Creative Commons Attribution License, which permits unrestricted use, distribution, and reproduction in any medium, provided the original work is properly cited.

\begin{abstract}
Paeonol is a phenolic compound derived from Paeonia suffruticosa Andrews (MC) and P. lactiflora Pall (PL). Paeonol can reduce cerebral infarction volume and improve neurological deficits through antioxidative and anti-inflammatory effects. However, the anti-inflammatory pathway of paeonol remains unclear. This study investigated the relationship between anti-inflammatory responses of paeonol and signaling pathways of TLR2 and TLR4 in cerebral infarct. We established the cerebral ischemiareperfusion model in Sprague Dawley rats by occluding right middle cerebral artery for $60 \mathrm{~min}$, followed by reperfusion for $24 \mathrm{~h}$. The neurological deficit score was examined, and the brains of the rats were removed for cerebral infarction volume and immunohistochemistry (IHC) analysis. The infarction volume and neurological deficits were lower in the paeonol group (pretreatment with paeonol; $20 \mathrm{mg} / \mathrm{kg}$ i.p.) than in the control group (without paeonol treatment). The IHC analysis revealed that the number of TLR2-, TLR4-, Ibal-, NF- $\kappa \mathrm{B}-(\mathrm{P} 50-)$, and IL-1 $\beta$-immunoreactive cells and TUNEL-positive cells was significantly lower in the paeonol group; however, the number of TNF- $\alpha$-immunoreactive cells did not differ between the paeonol and control groups. The paeonol reveals some neuroprotective effects in the model of ischemia, which could be due to the reduction of many proinflammatory receptors/mediators, although the mechanisms are not clear.
\end{abstract}

\section{Introduction}

Stroke generally causes a permanent disability and is the second leading cause of death worldwide. Moreover, approximately $70 \%$ of patients experience ischemic stroke. The only approved medicine for ischemic stroke is recombinant tissue plasminogen activator (rt-PA) $[1,2]$. However, the time window of rt-PA is narrow; thus, it should be injected within
$3 \mathrm{~h}$ after stroke onset. Moreover, it can be administered only to a limited proportion of patients with stroke who meet strict criteria, and it increases the risk of intracranial hemorrhage in patients after receiving thrombolysis [3]. Increasing evidence has shown that thrombolysis alone is not adequate for ischemic stroke. The reperfusion phase may also create a second damage through aggravating inflammatory responses, oxidative stress, and brain edema $[1,4,5]$. Thus, a novel 
therapy that can improve the second damage progression should be developed.

Inflammation is an essential step in the progression of neural death after ischemic stroke, which is characterized by the production of cytokines, chemokines, and adhesion molecules that amplify tissue damage $[6,7]$. Emerging in vivo and in vitro studies have highlighted that toll-like receptor (TLR) 2 (TLR2) and TLR4 have crucial roles in modulating postischemic inflammatory responses [8-10]. The extracellular domains of TLR2 and TLR4 can recognize both exogenous pathogen-associated molecular patterns (PAMPs) and endogenous damage-associated molecular patterns (DAMPs). Upon activation, microglial cells start expressing TLR2 and TLR4 on their surfaces. The binding of DAMPs to TLR2 and TLR4 initiates the signal transduction through myeloid differentiation factor 88 (MyD88). This leads to the degradation of inhibitor of kappa $\mathrm{B}(\mathrm{I} \kappa \mathrm{B})$ and the triggering translocation of nuclear factor $-\kappa \mathrm{B}(\mathrm{NF}-\kappa \mathrm{B})$ into the nucleus, which induces the production of proinflammatory cytokines such as interleukin-1 $\beta$ (IL-1 $\beta$ ), IL-6, and tumor necrosis factor- $\alpha$ (TNF- $\alpha)$ [11]. Clinical studies have reported that the expression levels of TLR2 and TLR4 in peripheral blood in the acute stage are related to the severity and prognosis of patients in the following stage $[12,13]$.

Paeonol is a type of a phenolic compound isolated from Paeonia suffruticosa Andrews and P. lactiflora Pall. Paeonol possesses diverse biological activities including antioxidative, anti-inflammatory, and anticoagulative effects [14-16]. We previously reported that paeonol pretreatment can reduce infarction volume and improve neurological deficits by scavenging superoxide anions and inhibiting microglial activation and IL- $1 \beta$ production in cerebral ischemia-reperfusion injured rats [17]. However, no study has evaluated the effect of paeonol on TLR2 and TLR4 signaling pathways. Therefore, this study investigated whether paeonol can ameliorate inflammatory responses following cerebral ischemiareperfusion injuries through the suppression of TLR2 and TLR4 signaling pathways. This study may increase our understanding about the neuroprotective mechanism of paeonol in cerebral ischemia-reperfusion injuries, which could be used to develop a novel agent for patients with stroke.

\section{Materials and Methods}

2.1. Animals. Adult male Sprague Dawley (SD) rats, weighing 290-320 g, were obtained from BioLASCO Co., Ltd., Taiwan. The rats were housed in the animal center of China Medical University (CMU) in a 12/12 h light-dark cycle at a constant temperature of $22 \pm 2^{\circ} \mathrm{C}$ and humidity of $55 \% \pm 5 \%$. They were provided ad libitum access to water and food. All experiments were performed following guidelines approved by the Institutional Animal Care and Use Committee of CMU.

2.2. Paeonol Preparation. Paeonol was extracted from the root bark of $P$. suffruticosa and the structure of paeonol was confirmed by NMR spectral analysis (Figure 1) in the laboratory room of Professor Tsai, Tung-Hu, National YangMing University, Taipei, Taiwan. In summary, the root bark
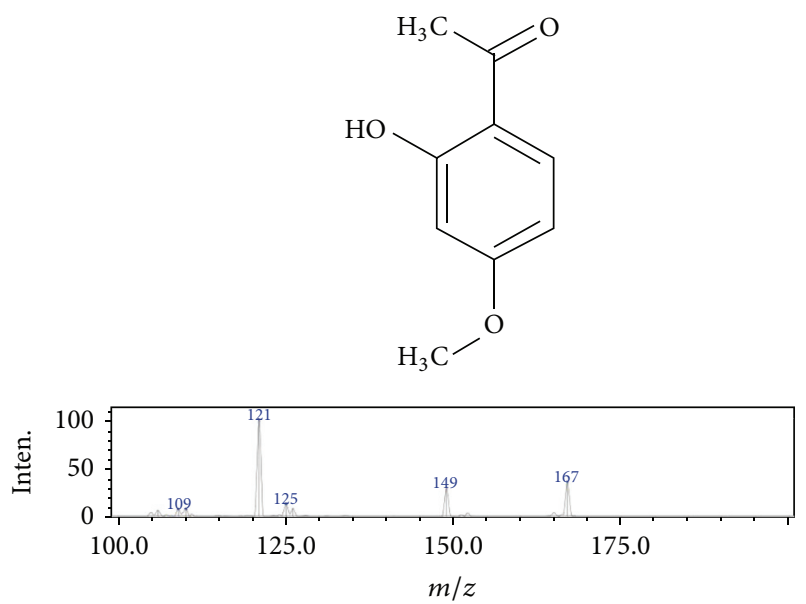

FIgURE 1: Spectral analysis of paeonol structure. Chemical names: $2^{\prime}$-hydroxy- $4^{\prime}$-methoxyacetophenone; molecular formula: $\mathrm{C}_{9} \mathrm{H}_{10} \mathrm{O}_{3}$; molecular weight: $166.1739 \mathrm{~g} / \mathrm{mol}$; ionization mode: ESI (+); collision energy: -25 .

of $P$. suffruticosa was extracted with $95 \%$ ethanol, and then the extracts were combined and concentrated in vacuo, followed by partitioning against $n$-hexane that was described by Hsieh et al. (2006) [17]. The dose response study for this paeonol was reported in our previous study. Therefore, this study used this effective dose only [17]. The $10 \mathrm{mg}$ of paeonol was dissolved in $150 \mu \mathrm{L}$ of glycofurol and then diluted in $4.85 \mathrm{~mL}$ of phosphate-buffered saline (PBS) to reach a final concentration of $2 \mathrm{mg} / \mathrm{mL}$.

2.3. Establishment of Cerebral Ischemia-Reperfusion Injured Model. The intraluminal transient middle cerebral artery (MCA) occlusion model was established in SD rats as previously described [18]. Briefly, all animals were anesthetized using 5\% isoflurane (Aerrane, Canada) and maintained using $2 \%$ isoflurane. A PE-50 catheter was introduced into the right femoral artery to monitor physiological parameters. After the midline neck incision, the right common carotid artery (CCA), ipsilateral internal carotid artery (ICA), and external carotid artery (ECA) were isolated from around the tissue, and the pterygopalatine artery was ligated close to its origin. A 3-0 nylon with a tip, blunted by a flame and coated with poly-L-lysine (UNIK, Taiwan), was inserted from the right ECA through the CCA and advanced into the ICA at a distance of $18-22 \mathrm{~mm}$ to block the right MCA origin. The right parietal bone was drilled to obtain a shallow hole, located $5 \mathrm{~mm}$ laterally and $1 \mathrm{~mm}$ posteriorly to the bregma, and the probe of Laser-Doppler flowmetry (DRT4, Moor Instruments Inc., Wilmington, USA) was placed inside the hole. When the cerebral blood flow of the right MCA distribution area decreased to less than $10 \%$ of the baseline value, the blood flow of the right MCA was blocked. The blood flow of the right MCA was blocked for $60 \mathrm{~min}$, and then the nylon was removed to allow reperfusion.

2.4. Monitoring of Physiological Parameters. Rectal temperature, heart rate, arterial blood pressure, arterial blood gas 
(including $\mathrm{pH}, \mathrm{pO}_{2}$, and $\mathrm{pCO}_{2}$ ), and blood sugar levels were measured $10 \mathrm{~min}$ before and $60 \mathrm{~min}$ after occluding the blood flow of the right MCA and 10 min after the reperfusion.

2.5. Grouping and Experiments. A total of $36 \mathrm{SD}$ rats were randomly divided into the following three groups evenly: (1) sham group: the right CCA and ICA were exposed without occluding the blood flow of the right MCA; (2) control group: the methods were identical to those of the sham group; however, the blood flow of the right MCA was occluded for $60 \mathrm{~min}$ and then reperfusion was performed for $24 \mathrm{~h}$; and (3) paeonol group: the methods were identical to those of the control group; however, paeonol $(20 \mathrm{mg} / \mathrm{kg})$ was intraperitoneally administrated $20 \mathrm{~min}$ prior to occluding the blood flow of the right MCA. Besides, both sham group and control group received administration with the same volume $(10 \mathrm{~mL} / \mathrm{kg})$ of $3 \%$ glycofurol in PBS $20 \mathrm{~min}$ before the procedure.

All of $36 \mathrm{SD}$ rats were evaluated for their neurological status $24 \mathrm{~h}$ after reperfusion, and then the rats were sacrificed to obtain their brains. Each group has 12 SD rats. The 6 SD rats of each group were used to measure their cerebral infarction volume, and the other 6 SD rats of each group were used for immunohistochemistry (IHC) and TUNEL assay study. Moreover, two rats of the control group were randomly selected for double immunofluorescence analysis.

2.6. Evaluation of Neurological Status. All of the 36 SD rats' neurological status were examined by a well-trained person who was blinded to the groups $24 \mathrm{~h}$ after the reperfusion according to the modified neurological severity score as described by Chen et al. [19]. The examination included motor test [raising the rat by the tail $(0-3)$; placing the rat on the floor $(0-3)]$, sensory test $(0-2)$, beam balance test $(0-$ 6 ), and reflex test $(0-4)$. The overall neurological function of each rat was graded from 0 to 18 .

2.7. Measurement of Infarction Volume. After examining the neurological status, $6 \mathrm{SD}$ rats of each group were anesthetized using chloral hydrate $(400 \mathrm{mg} / \mathrm{mL})$, followed by transcardial perfusion by using $200 \mathrm{~mL}$ of $0.9 \%$ saline. Then, the brains were removed, coronally sliced into $2 \mathrm{~mm}$ thick slices, stained using 2\% 2,3,5-triphenyl tetrazolium chloride (TTC, Merck, Germany) for $15 \mathrm{~min}$ at $37^{\circ} \mathrm{C}$, and fixed in $4 \%$ paraformaldehyde (PFA). Under the TTC staining, the infarcted brain tissue remains originally pale, whereas the viable tissue becomes deep red. The infarction and total brain volume were quantified using a microscopic image analysis software (Image $1.47 \mathrm{v}$, USA). The cerebral infarction volume was represented as a percentage of the infarcted tissue relative to the total brain tissue.

2.8. Immunohistochemistry. After examining the neurological status, $6 \mathrm{SD}$ rats of each group were anesthetized using chloral hydrate $(400 \mathrm{mg} / \mathrm{mL})$ and transcardially perfused using $200 \mathrm{~mL}$ of $0.9 \%$ saline, followed by $200 \mathrm{~mL}$ of $4 \%$ PFA ( $\mathrm{pH}$ 7.4). The brain tissues were postfixed in $4 \%$ PFA at $\mathrm{pH}$ 7.4 overnight and were transferred for dehydration in $30 \%$ sucrose for 3 days. The brains were embedded in a tissuefreezing medium (OCT compound, Triangle Biomedical Science, USA), frozen at $-20^{\circ} \mathrm{C}$, cut into $14-\mu \mathrm{m}$ coronal sections by using a cryostat (CM3050S, Leica, USA), and stored at $-80^{\circ} \mathrm{C}$. Six rats of each group were employed, and 20 slides of each rat were captured for IHC.

The brain sections were rinsed with $\mathrm{PBS}$ for $3 \mathrm{~min}$ and immersed in $3 \% \mathrm{H}_{2} \mathrm{O}_{2}$ /methanol for 15 min to inhibit endogenous peroxide activity. Thereafter, the sections were incubated with $10 \%$ normal animal serum (A kit, LsAB kit, Zymed, USA) for $10 \mathrm{~min}$ at room temperature. The sections were, respectively, incubated with primary anti-TLR2 $(1: 100$ dilution, OriGene-Antibody, USA) overnight at $4^{\circ} \mathrm{C}$, antiTLR4 (1:200 dilution, Abcam, USA) overnight at $4^{\circ} \mathrm{C}$, antiIbal (1:1000 dilution, Abcam, USA) for $1 \mathrm{~h}$ at room temperature, anti-NF- $\kappa$ B (p50; 1:200 dilution, Santa Cruz, USA) overnight at $4^{\circ} \mathrm{C}$, anti-IL-1 $\beta(1: 200$ dilution, Santa Cruz, USA) overnight at $4^{\circ} \mathrm{C}$, and anti-TNF- $\alpha(1: 200$ dilution, Santa Cruz, USA) overnight at $4^{\circ} \mathrm{C}$ and washed with PBS three times. After incubation with secondary antibodies (B kit, LsABkit, Zymed, USA) and the avidin-biotin peroxidase complex ( $\mathrm{C}$ kit, LsAB kit, Zymed, USA), the sections were stained using 3,3-diaminobenzidine kit (Scytek Laboratories, USA) and counterstained with hematoxylin. The stained sections were mounted using mounting media (AssistantHistokitt, Germany), and the number of immunoreactive cells, within the penumbra areas of $1 \mathrm{~mm}^{2}$, was calculated under a quick scan of ScanScope (CS2, Aperio, USA). The negative control stain was subjected to the same IHC assay on the adjacent section of the control group without active TLR2, TLR4, NF- $\kappa$ B, IL-1 $\beta$, and TNF- $\alpha$ antibody.

2.9. TUNEL Assay. Six SD rats of each group were used to TUNEL assay, which was used to detect DNA fragmentation in the penumbra areas. TUNEL staining was performed according to the manufacturer's instructions (Calbiochem). Briefly, the brain sections were incubated with $20 \mu \mathrm{g} / \mathrm{mL}$ proteinase $\mathrm{K}$ for $20 \mathrm{~min}$ at room temperature, rinsed with TBS, incubated with $1 \mathrm{x}$ TdT equilibration buffer for $30 \mathrm{~min}$ at room temperature, and then incubated with TdT-labeling reaction mixture for $1.5 \mathrm{~h}$ at $37^{\circ} \mathrm{C}$. After adding the stop solution and blocking buffer, the sections were incubated with $1 \mathrm{x}$ conjugate solution for $30 \mathrm{~min}$ at room temperature, and TUNEL-positive cells were visualized using the DAB kit. Finally, the sections were counterstained with methyl green and mounted using mounting media. The TUNEL-positive cells were calculated using the same method as that used in the IHC assay.

2.10. Double Immunofluorescence Analysis. Two SD rats of the control group were randomly selected for double immunofluorescence analysis. The brain sections were blocked for 10 min in PBS containing 10\% bovine serum albumin (Sigma, USA). The sections were then incubated overnight at $4^{\circ} \mathrm{C}$ with primary antibodies $[1: 100$ rabbit polyclonal anti-TLR2 (OriGene-Antibody, USA), 1:100 mouse monoclonal antiTLR4 (Abcam, USA), and 1:500 goat polyclonal anti-Iba1 (Abcam, USA)]. Further, the sections were incubated with 
TABLE 1: Physiological parameters.

\begin{tabular}{|c|c|c|c|c|c|c|c|}
\hline & $\begin{array}{c}\mathrm{BT} \\
\left({ }^{\circ} \mathrm{C}\right) \\
\end{array}$ & $\begin{array}{c}\text { HR } \\
\text { (beats/min) }\end{array}$ & $\begin{array}{c}\text { MABP } \\
(\mathrm{mmHg})\end{array}$ & $\mathrm{pH}$ & $\begin{array}{c}\mathrm{pO}_{2} \\
(\mathrm{mmHg})\end{array}$ & $\begin{array}{c}\mathrm{pCO}_{2} \\
(\mathrm{mmHg})\end{array}$ & $\begin{array}{c}\text { BS } \\
(\mathrm{mg} / \mathrm{dl})\end{array}$ \\
\hline \multicolumn{8}{|c|}{ Preischemia $10 \mathrm{~min}$} \\
\hline Sham & $36.9 \pm 0.5$ & $328.3 \pm 27.1$ & $96.9 \pm 12$ & $7.41 \pm 0.04$ & $401.0 \pm 94.6$ & $41.3 \pm 8.3$ & $128.6 \pm 26.6$ \\
\hline Control & $37.2 \pm 0.5$ & $357.0 \pm 46.2$ & $100.8 \pm 8.8$ & $7.43 \pm 0.03$ & $411.9 \pm 54.7$ & $42.6 \pm 4.5$ & $139.4 \pm 34.3$ \\
\hline Paeonol & $36.9 \pm 0.5$ & $346.8 \pm 51.1$ & $97.4 \pm 9.5$ & $7.42 \pm 0.03$ & $434.3 \pm 49.6$ & $41.9 \pm 4.8$ & $131.9 \pm 30.3$ \\
\hline \multicolumn{8}{|c|}{ Ischemia $60 \mathrm{~min}$} \\
\hline Sham & $34.8 \pm 0.7$ & $323.6 \pm 69.3$ & $90.3 \pm 10.7$ & $7.29 \pm 0.12$ & $394.1 \pm 97.2$ & $56.3 \pm 18.9$ & $115.1 \pm 29.4$ \\
\hline Control & $35.2 \pm 0.6$ & $364.3 \pm 46.0$ & $92.9 \pm 10.0$ & $7.32 \pm 0.07$ & $408.9 \pm 51.9$ & $52.5 \pm 12.0$ & $123.4 \pm 36.4$ \\
\hline Paeonol & $35.1 \pm 0.7$ & $346.3 \pm 44.9$ & $90.2 \pm 7.90$ & $7.33 \pm 0.07$ & $404.3 \pm 62.6$ & $49.0 \pm 11.0$ & $120.1 \pm 28.6$ \\
\hline \multicolumn{8}{|c|}{ Reperfusion 10 min } \\
\hline Sham & $35.3 \pm 0.9$ & $317.9 \pm 65.2$ & $96.4 \pm 19.7$ & $7.33 \pm 0.10$ & $378.7 \pm 128.7$ & $53.0 \pm 16.1$ & $53.0 \pm 16.1$ \\
\hline Control & $35.5 \pm 0.8$ & $346.3 \pm 55.4$ & $93.1 \pm 9.3$ & $7.34 \pm 0.06$ & $412.3 \pm 73.2$ & $50.9 \pm 9.6$ & $50.9 \pm 9.6$ \\
\hline Paeonol & $35.5 \pm 0.5$ & $348.9 \pm 33.0$ & $95.3 \pm 5.9$ & $7.34 \pm 0.06$ & $360.8 \pm 110.3$ & $43.4 \pm 9.1$ & $43.4 \pm 9.1$ \\
\hline
\end{tabular}

Physiological parameters are expressed as mean \pm SD ( $n=12$ for each group) and were measured 10 min before and 60 min after occluding the blood flow of the right middle cerebral artery and $10 \mathrm{~min}$ after reperfusion. Sham: sham group; control: control group; paeonol: paeonol group; BT: body temperature; HR: heart rate; MABP: mean arterial blood pressure; BS: blood sugar.

secondary antibodies [1:800 Alexa Fluor 488-conjugated donkey anti-rabbit, 1:800 Alexa Fluor 488-conjugated donkey anti-mouse, and 1:800 $\mathrm{Cy}^{\mathrm{TM}}$ 3-conjugated donkey antigoat (Jackson ImmunoResearch Lab. Inc., USA)] for $1 \mathrm{~h}$ at room temperature. Each of the abovementioned steps was followed by three $3-\mathrm{min}$ rinses in $0.01 \%$ Tween $20 / \mathrm{PBS}$. At the end of the procedure, the sections were covered with coverslip using a mounting medium (SIGMA, USA) containing DAPI to counterstain DNA in the nuclei and dried overnight. The confocal images were captured using a laser-scanning confocal microscope (Leica TCS SP2, Germany).

2.11. Statistical Analysis. Data are expressed as mean \pm standard deviation. Data from all the experimental groups were compared using one-way ANOVA followed by post hoc Scheffe's test. A probability value of less than 0.05 was considered statistically significant.

\section{Results}

3.1. Physiological Parameters. The physiological parameters including rectal temperature, heart rate, arterial blood pressure, arterial blood gas $\left(\mathrm{pH}, \mathrm{pO}_{2}\right.$, and $\left.\mathrm{pCO}_{2}\right)$, and blood sugar levels did not significantly differ among sham, control, and paeonol groups at 10 before and $60 \mathrm{~min}$ after occluding the blood flow of the right MCA and at $10 \mathrm{~min}$ after the reperfusion (all $p>0.05$, Table 1 ).

3.2. Effect of Paeonol on Cerebral Infarction Volume and Neurological Deficits in Cerebral Ischemia-Reperfusion Injured Rats. The control and paeonol groups exhibited varying cerebral infarction volume percentages after undergoing occlusion of the right MCA for $60 \mathrm{~min}$, followed by reperfusion for $24 \mathrm{~h}$ (Figure $2(\mathrm{a})$ ). The cerebral infarction volume percentages in the sham, control, and paeonol groups were $1.53 \% \pm$ $0.48 \%, 29.39 \% \pm 2.85 \%$, and $15.42 \% \pm 1.35 \%$, respectively. The cerebral infarction volume percentages were higher in the control and paeonol groups than in the sham group (both $p<$ 0.001, Figure 2(b)). Furthermore, compared with the control, treatment with paeonol significantly reduced the cerebral infarction volume percentage $(p<0.001$; Figure $2(\mathrm{~b}))$.

The rats in the control and paeonol groups developed different severities of neurological deficits after undergoing occlusion of the right MCA for $60 \mathrm{~min}$, followed by reperfusion for $24 \mathrm{~h}$. The modified neurological severity scores in the sham, control, and paeonol groups were $0.00 \pm 0.00,10.58 \pm$ 0.67 , and $6.57 \pm 0.97$, respectively. The modified neurological severity scores were higher in the control and paeonol groups than in the sham group (both $p<0.001$, Figure 2(c)). The scores in the paeonol group were significantly lower than those in the control group $(p<0.001$; Figure 2(c)).

3.3. Effect of Paeonol on the Number of TLR2-, TLR4-, and Ibal-Immunoreactive Cells within the Cortical Penumbra in Cerebral Ischemia-Reperfusion Injured Rats. All immunoreactive cells were counted within the dotted line area of $1 \mathrm{~mm}^{2}$ (counts/1 $\mathrm{mm}^{2}$; Figure 3).

The number of TLR2-immunoreactive cells in the sham, control, and paeonol groups was $70.8 \pm 13.2,301.2 \pm$ 63.3 , and $172.5 \pm 65.9$, respectively. The number of TLR2immunoreactive cells was significantly higher in the control and paeonol groups than in the sham group $(p<0.001$ and $p<0.05$, respectively; Figures 4(a) and 4(b)). Moreover, there were significantly fewer immunoreactive cells in the paeonol group than in the control group $(p<0.01$; Figures 4 (a) and $4(\mathrm{~b}))$.

The number of TLR4-immunoreactive cells in the sham, control, and paeonol groups was $35.2 \pm 7.0,586.7 \pm 128.7$, and $197.3 \pm 86.3$, respectively. The number of TLR4-immunoreactive cells was significantly higher in the control and paeonol groups than in the sham group $(p<0.001$ and $p<0.05$, respectively; Figures 4(a) and 4(b)). Moreover, there 


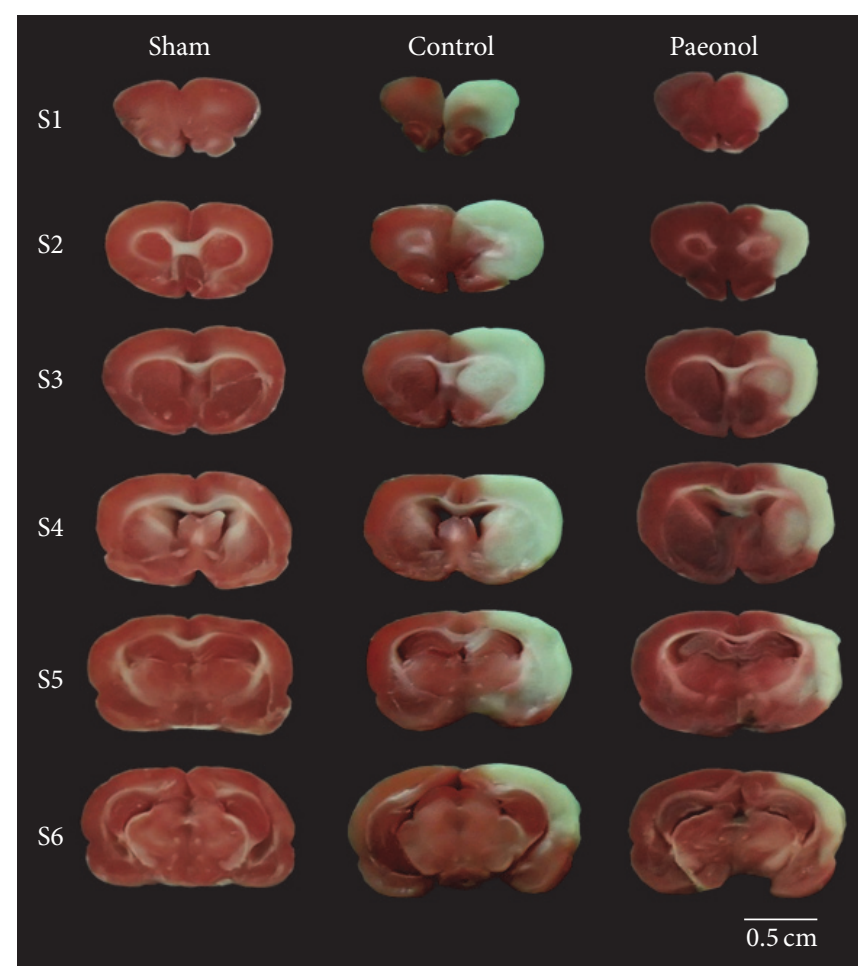

(a)

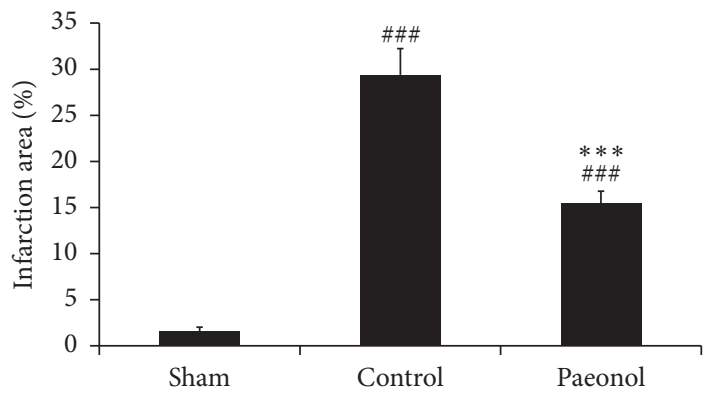

(b)

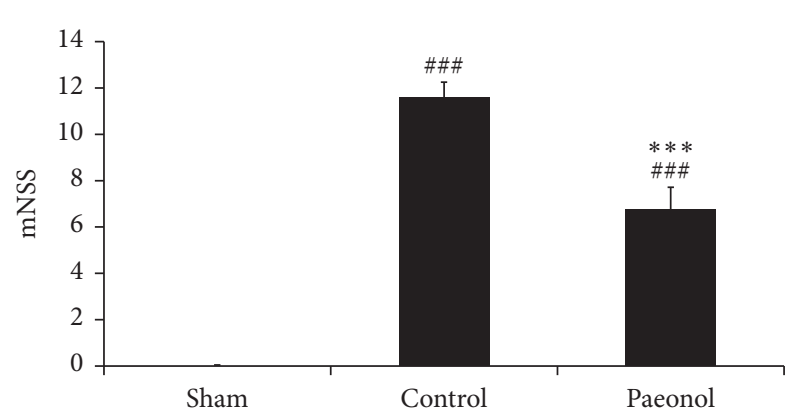

(c)

FIGURE 2: Effect of paeonol on cerebral infarction volume and neurological deficits in cerebral ischemia-reperfusion injured rats. (a) Representative photo showed TTC-stained brain slices in each group $(n=6)$. The infarcted tissue remained originally pale, whereas the viable tissue became deep red. (b) Quantitative analysis of cerebral infarction volume percentage $(n=6)$ showed smaller percentage in paeonol group compared with control group. (c) Quantitative analysis of modified neurological severity score $(n=12)$ in paeonol group was significantly lower than control group. Data are expressed as mean \pm SD. ${ }^{\# \# \#} p<0.001$ compared with the sham group; ${ }^{* * *} p<0.001$ compared with the control group. Scale bar $=0.5 \mathrm{~cm}$.

were significantly fewer immunoreactive cells in the paeonol group than in the control group $(p<0.001$; Figures $4(\mathrm{a})$ and $4(\mathrm{~b}))$.

The number of Ibal-immunoreactive cells in the sham, control, and paeonol groups was $202.3 \pm 66.4,402.0 \pm$ 78.5 , and $259.5 \pm 66.0$, respectively. The number of Ibalimmunoreactive cells was significantly lower in the paeonol group than in the control group ( $p<0.05$; Figures $4(a)$ and $4(b))$, and it did not significantly differ between the sham and paeonol groups ( $p>0.05$; Figures $4(\mathrm{a})$ and $4(\mathrm{~b})$ ).

3.4. Effect of Paeonol on the Number of NF- $\kappa B$-, IL-1 $\beta$-, and TNF- $\alpha$-Immunoreactive Cells within the Cortical Penumbra in Cerebral Ischemia-Reperfusion Injured Rats. The number of NF- $\kappa \mathrm{B}$-immunoreactive cells in the sham, control, and paeonol groups was $2.7 \pm 2.6,86.0 \pm 67.7$, and $15.2 \pm 11.7$, respectively. The number of $\mathrm{NF}-\kappa \mathrm{B}$-immunoreactive cells was significantly lower in the paeonol group than in the control group ( $p<0.05$; Figures 5(a) and 5(b)), and it did not significantly differ between the sham and paeonol groups $(p>0.05$; Figures 5(a) and 5(b)).

The number of IL- $1 \beta$-immunoreactive cells in the sham, control, and paeonol groups was $3.7 \pm 2.7,40.2 \pm 7.8$, and $7.8 \pm 4.5$, respectively. The number of IL- $1 \beta$-immunoreactive cells was significantly lower in the paeonol group than in the control group ( $p<0.001$; Figures $5(\mathrm{a})$ and $5(\mathrm{~b})$ ), and it did not significantly differ between the sham and paeonol groups $(p>0.05$; Figures 5(a) and 5(b)). 


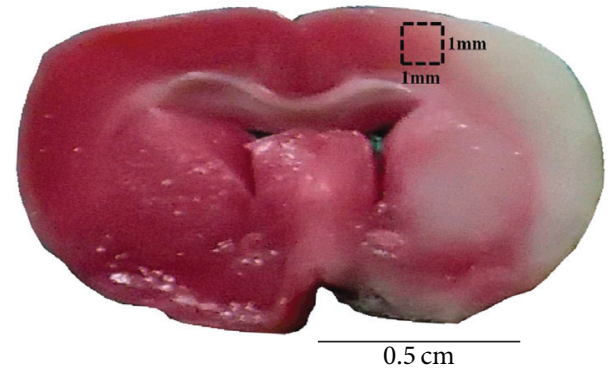

FIGURE 3: Representative photo showed the brain coronal section located $0.72 \mathrm{~mm}$ posterior to the bregma position. The dashed line square, located $2 \mathrm{~mm}$ laterally to the midline, within the cerebral penumbral zone indicated the region for calculating immunoreactive cells. The length and width of dashed line square $=1 \mathrm{~mm}$. Scale bar $=0.5 \mathrm{~cm}$.

The number of TNF- $\alpha$-immunoreactive cells in the sham, control, and paeonol groups was $17.0 \pm 20.7,249.7 \pm 122.8$, and $173.8 \pm 40.7$, respectively. The number of TNF- $\alpha$-immunoreactive cells was significantly higher in the control and paeonol groups than in the sham group $(p<0.001$ and $p<0.05$, respectively; Figures 5(a) and 5(b)), and it did not significantly differ between the control and paeonol groups $(p>0.05$; Figures 5(a) and 5(b)).

3.5. Effect of Paeonol on TUNEL-Positive Cells within the Cortical Penumbra in Cerebral Ischemia-Reperfusion Injured Rats. TUNEL assay was used to detect apoptotic cells $24 \mathrm{~h}$ after reperfusion. The number of TUNEL-positive cells in the sham, control, and paeonol groups was $6.5 \pm 6.2,473.7$ \pm 198.2 , and $88.8 \pm 97.7$, respectively, in the ipsilateral hemisphere. No TUNEL-positive cells were observed in the contralateral hemisphere (Figures 6(a) and 6(b)). The number of TUNEL-positive cells was significantly lower in the paeonol group than in the control group in the ipsilateral hemisphere $(p<0.001$; Figures 6(a) and 6(b)), and it did not significantly differ between the sham and paeonol groups in the ipsilateral hemisphere $(p>0.05$; Figures 6(a) and 6(b)).

3.6. Effect of Paeonol on Double Immunofluorescence Analysis in Cerebral Ischemia-Reperfusion Injured Rats. To evaluate whether TLR2 and TLR4 are related to activating microglia after the ischemia-reperfusion injury, double immunofluorescence analysis was performed. The double immunofluorescence analysis of the brain sections, adjacent to the sections used for IHC analysis, revealed the colocalization of TLR2 staining with Ibal in the cortical penumbra $24 \mathrm{~h}$ after reperfusion (Figure 7(a)). By contrast, no colocalization of TLR4 staining with Ibal was observed (Figure 7(b)).

\section{Discussion}

The results of the present study indicated that paeonol pretreatment can reduce cerebral infarction volume; neurological deficits; TLR2-, TLR4-, Ibal-, NF- $\kappa$ B-, and IL-1 $\beta-$ immunoreactive cell numbers; and TUNEL-positive cells in cerebral ischemia-reperfusion injured rats. These results are consistent with those of our previous study that paeonol pretreatment can reduce cerebral infarction volume and neurological deficits, scavenge superoxide anions, and inhibit microglial activation and IL-1 $\beta$ production [17]. Inflammation is an essential step in the progression of neural damage after cerebral ischemia-reperfusion injuries, which is characterized by the production of cytokines, chemokines, and adhesion molecules that amplify tissue damage [20]. Emerging clinical and experimental studies have highlighted the key roles of TLR2 and TLR4 in microglia, which contribute to inflammatory responses occurring after cerebral ischemia-reperfusion injuries [21-23]. The expression of TLR2 and TLR4 in microglia contributes to neuronal damage in cerebral ischemia-reperfusion injuries [21-23]. Moreover, accumulating evidence indicated that the effective suppression of TLR2 and TLR4 signaling pathways in microglia can provide neuroprotection [24-28].

Microglia are resident macrophage-like cells in the central nervous system [29]. During an ischemic stroke, microglia can be activated within minutes and reaches a peak after 2 to 3 days [30]. Microglia has both detrimental and beneficial effects at different time points. In early activation, microglia produces inflammatory substances leading to cell death, whereas in later activation, it produces transforming growth factor-beta 1 and acts as a neuroprotective agent $[22,30]$. Upon activation, microglia begins expressing TLR2 and TLR4 on its surface. In response to DAMPs, which are released by necrotic cells, the signal transduction of TLR2 and TLR4 is induced through MyD88, resulting in the degradation of $\mathrm{I} \kappa \mathrm{B}$ and the translocation of NF- $\kappa \mathrm{B}$ into the nucleus; this induces the production of proinflammatory cytokines such as IL-1 $\beta$, IL- 6 , and TNF- $\alpha$ [11, 20]. Several studies have reported the effective inhibition of TLR2 and TLR4 expression in different models that exhibited decreased NF- $\kappa \mathrm{B}$ activity and proinflammatory cytokine suppression corresponding with decreased tissue damage $[24,25,27,28]$.

IL- $1 \beta$ can be observed $2-6 \mathrm{~h}$ after cerebral ischemia and reaches a peak at $12-24 \mathrm{~h}[31,32]$. IL- $1 \beta$ is considered to be a neurotoxic mediator, which induces neuronal apoptosis and enhances chemokine expression in microglia and astrocytes $[4,31,33]$. Moreover, the inhibition of IL-1 $\beta$ production reduces infarction volume $[32,34]$. In the present study, a significantly higher number of Ibal-, TLR2-, TLR4-, NF$\kappa \mathrm{B}$-, IL- $1 \beta$-, and TNF- $\alpha$-immunoreactive cells and TUNELpositive cells were observed in the control group, which is in accordance with the results of previous studies. In addition, paeonol pretreatment significantly reduced the number of Ibal-, TLR2-, TLR4-, NF- $\kappa$ B-, and IL-1 $\beta$-immunoreactive cells and TUNEL-positive cells. Therefore, these results suggest that paeonol pretreatment can attenuate inflammatory responses through the suppression of TLR2 and TLR4 signaling pathways to ameliorate apoptosis within the penumbral area.

In our study, TNF- $\alpha$ levels did not significantly differ between the paeonol and control groups. TNF- $\alpha$ is another proinflammatory cytokine involved in cerebral ischemiareperfusion injuries. TNF- $\alpha$ gradually increases from 1 to $3 \mathrm{~h}$ after cerebral ischemia and reaches a peak at $24-36 \mathrm{~h}$ 


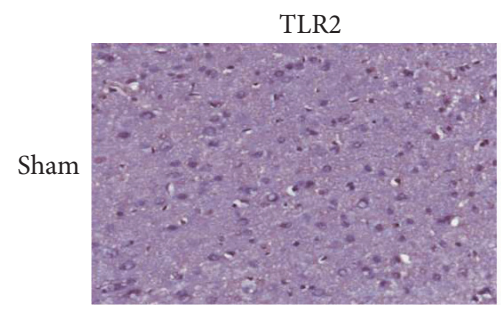

(A)

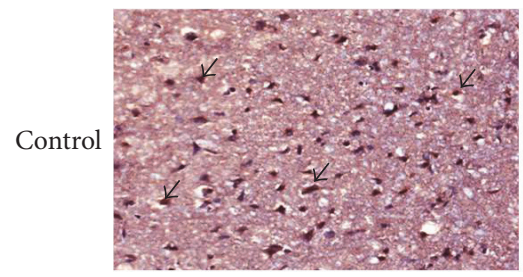

(B)

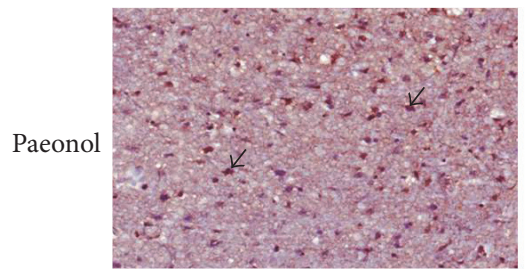

(C)
TLR4

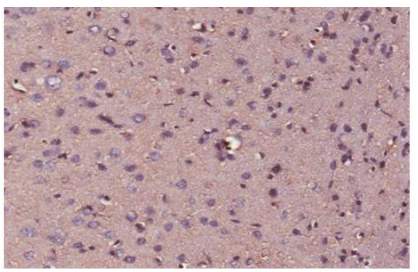

(D)

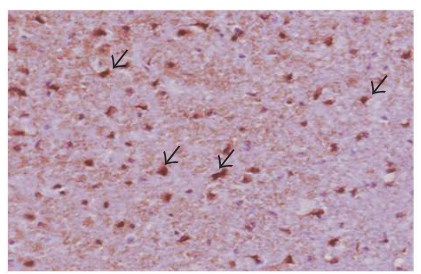

(E)

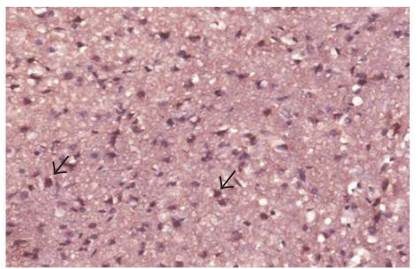

(F)

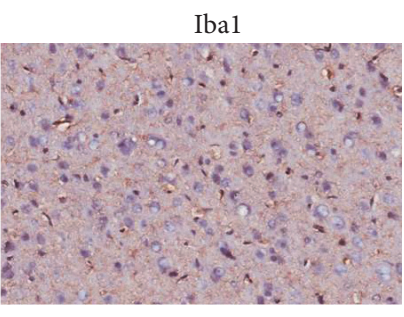

(G)

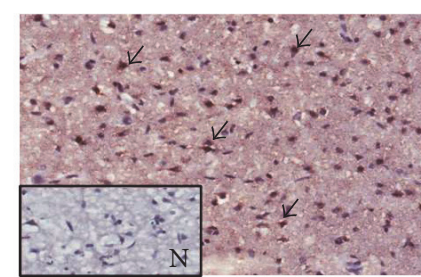

(H)

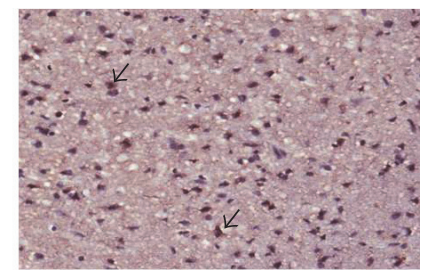

(I)

(a)

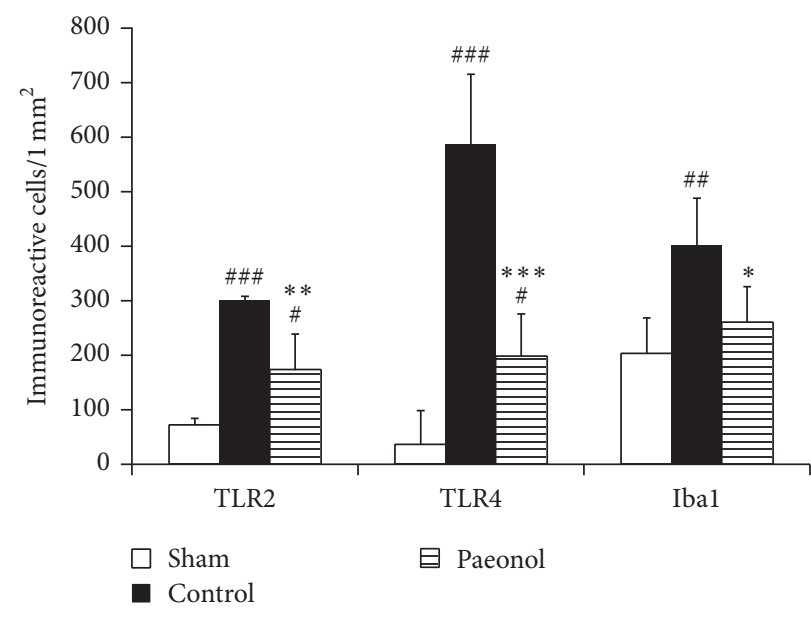

(b)

FIGURE 4: Effect of paeonol on the number of TLR2-, TLR4-, and Ibal-immunoreactive cells within the cortical penumbra in cerebral ischemia-reperfusion injured rats. (a) The numbers of TLR2-, TLR4-, and Ibal-immunoreactive cells (arrows) were lower in the paeonol group than in the control group. (200x); (b) the numbers of TLR2-, TLR4-, and Ibal-immunoreactive cells were significantly lower in the paeonol group than in the control group $(n=6)$. Data are expressed as mean $\pm \mathrm{SD}$. ${ }^{\# \#} p<0.001,{ }^{\# \#} p<0.01$, and ${ }^{\#} p<0.05$ compared with the sham group; ${ }^{* * *} p<0.001,{ }^{* *} p<0.01$, and ${ }^{*} p<0.05$ compared with the control group. N: negative control; sham: sham group; control: control group; paeonol: paeonol group.

[35-37]. Several studies have reported that TNF- $\alpha$ can function both as a neurotoxic and as a neuroprotective mediator $[38,39]$. TNF- $\alpha$ executes its neurotoxic function by promoting the production of oxygen free radicals and excitatory amino acids, which ultimately results in neuronal cell death. TNF- $\alpha$ deficiency and anti-TNF- $\alpha$ antibodies exert neuroprotective effects $[39,40]$. By contrast, another study reported that TNF- $\alpha$-knockout mice have a higher infarction volume [41]. It appears that TNF- $\alpha$ promotes inflammatory responses and is involved in the suppression of inflammatory signal transduction; in other words, TNF- $\alpha$ may regulate both proinflammation and anti-inflammation after cerebral ischemia-reperfusion injuries [41]. In the present study, a higher number of TNF- $\alpha$-immunoreactive cells and lower infarction volume and neurological deficits were observed in the paeonol group. However, the present study was limited 


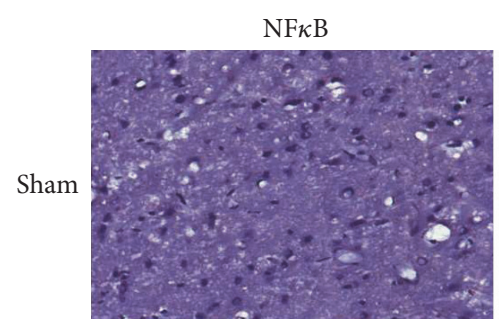

(A)

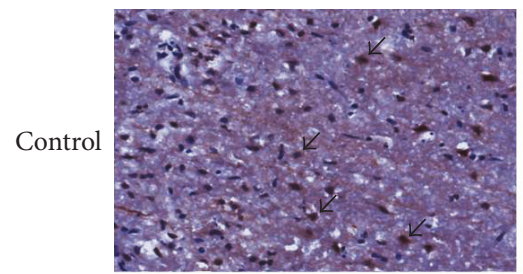

(B)

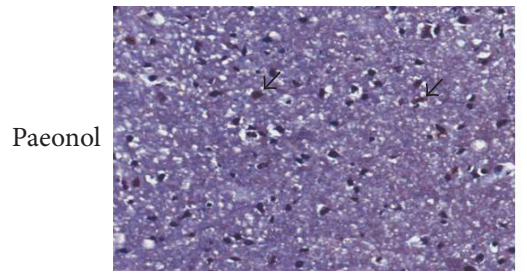

(C)
IL- $1 \beta$

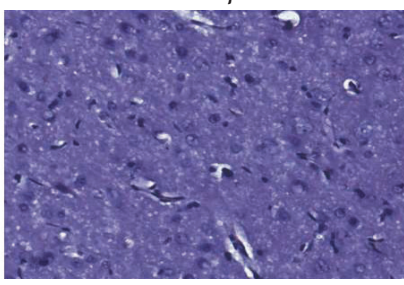

(D)

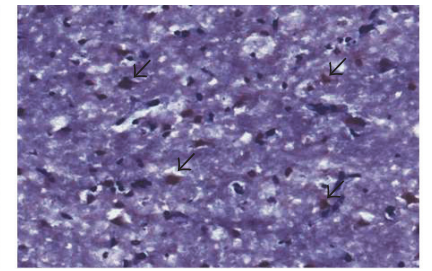

(E)

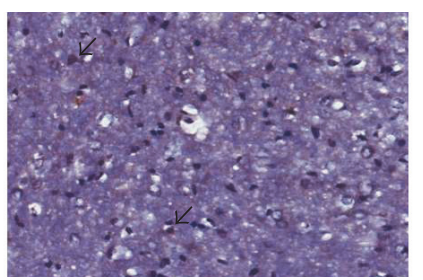

(F)

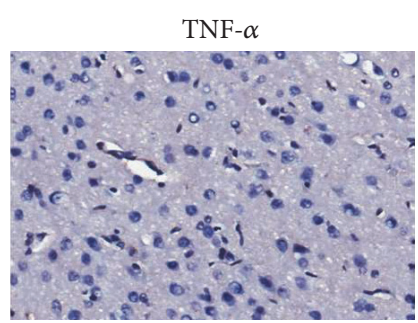

(G)

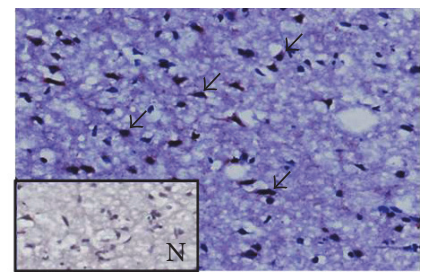

(H)

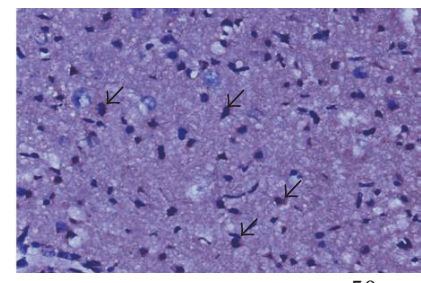

(I)

\section{$50 \mu \mathrm{m}$}

(a)

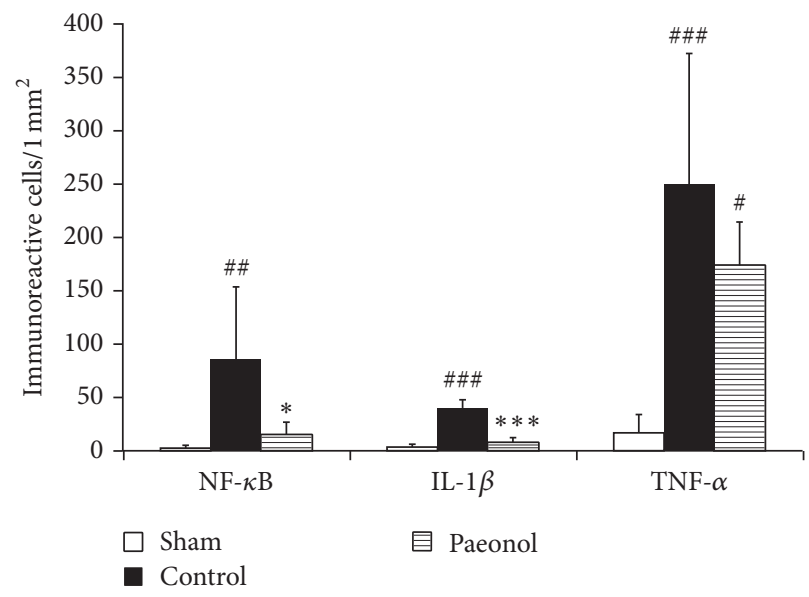

(b)

FIGURE 5: Effect of paeonol on the number of NF- $\kappa$ B-, IL-1 $\beta$-, and TNF- $\alpha$-immunoreactive cells within the cortical penumbra in cerebral ischemia-reperfusion injured rats. (a) The numbers of NF- $\kappa \mathrm{B}$ - and IL- $1 \beta$-immunoreactive cells (arrows) were lower in the paeonol group than in the control group, whereas the number of TNF- $\alpha$-immunoreactive cells (arrows) did not differ between the paeonol and control groups $(200 \mathrm{x})$; (b) the numbers of NF- $\kappa \mathrm{B}$ - and IL-1 $\beta$-immunoreactive cells were significantly lower in the paeonol group than in the control group $(n=6)$, whereas it did not significantly differ between the paeonol and control groups. Data are expressed as mean \pm SD. ${ }^{\# \#} p<0.001$ and ${ }^{\# \#} p<0.01$, and ${ }^{\#} p<0.05$ compared with the sham group; ${ }^{* * *} p<0.001$ and $^{*} p<0.05$ compared with the control group. N: negative control; sham: sham group; control: control group; paeonol: paeonol group.

only to $24 \mathrm{~h}$ after reperfusion. Therefore, a long-term observational study is required to understand the role of TNF- $\alpha$ in ischemic stroke treated with paeonol.

TLR2 is mainly upregulated in lesion-associated microglia 24-72 $\mathrm{h}$ after cerebral ischemia [42] but is also observed in astrocytes and endothelial cells [28]. Similar to TLR2, TLR4 is also significantly upregulated in microglia and astrocytes $24 \mathrm{~h}$ after cerebral ischemia [43]. Moreover, neurons express TLR2 and TLR4 $1 \mathrm{~h}$ after cerebral ischemia-reperfusion injuries $[23,42]$. In our study, we observed the colocalization of TLR2 staining with Ibal in the cortical penumbra area in the control group, which is in agreement with the results of 
TUNEL

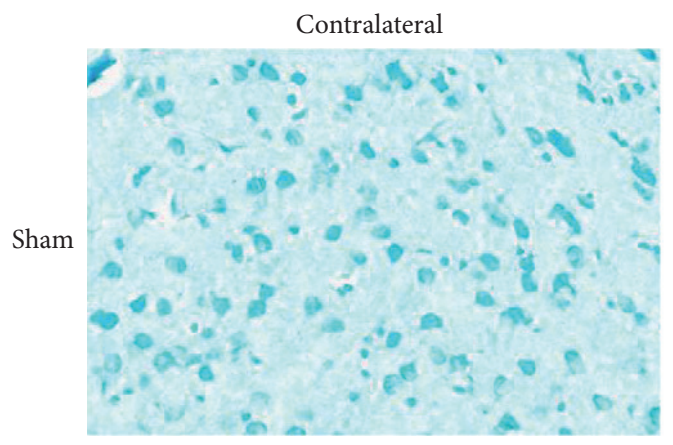

(A)

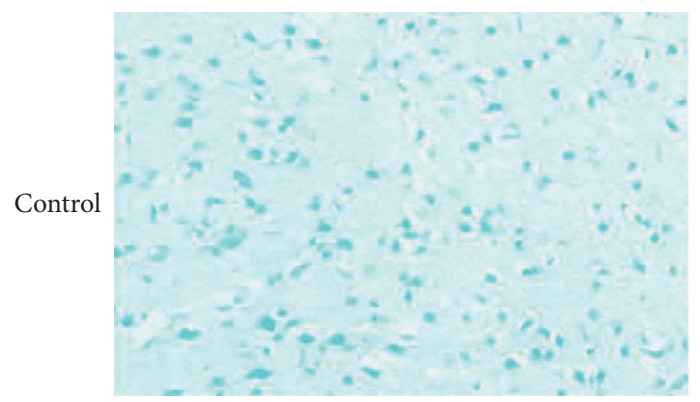

(B)

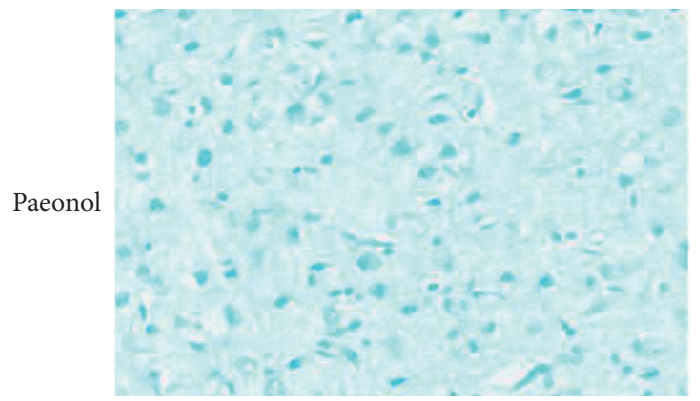

(C)

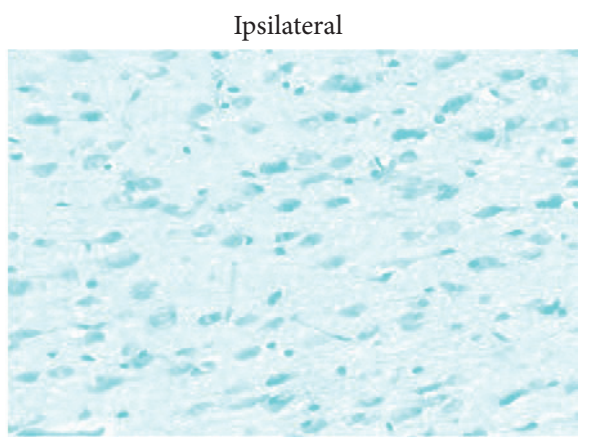

(D)

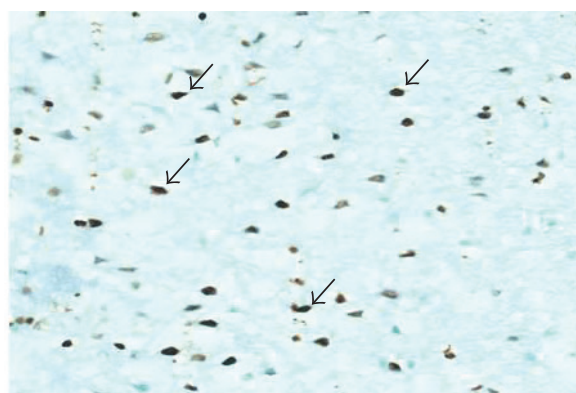

(E)

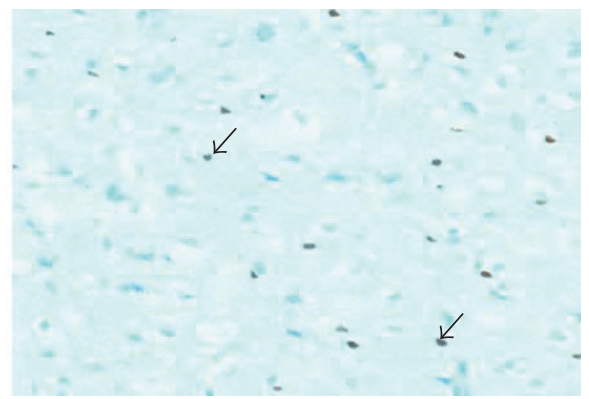

(F)

$50 \mu \mathrm{m}$

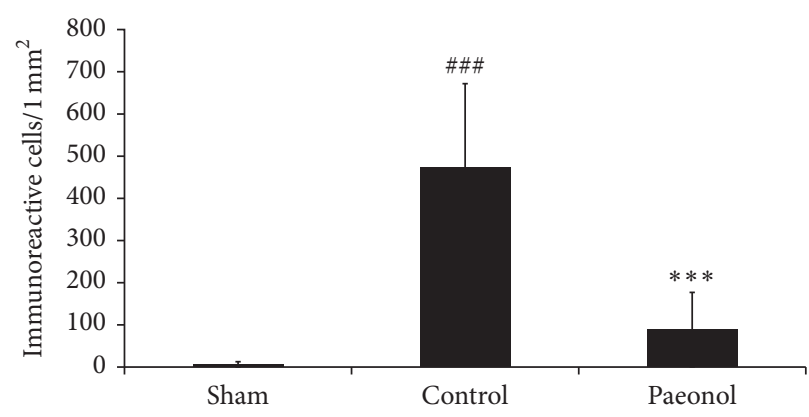

(b)

FIGURE 6: Effect of paeonol on apoptosis within the cortical penumbra in cerebral ischemia-reperfusion injured rats. (a) No TUNEL-positive cells were observed in the sham group and contralateral hemisphere. The number of TUNEL-positive cells (arrows) was lower in the paeonol group than in the control group. (b) The number of TUNEL-positive cells was significantly lower in the paeonol group than in the control group $(n=6)$. Data are expressed as mean \pm SD. ${ }^{\# \# \#} p<0.001$ compared with the sham group; ${ }^{* * *} p<0.001$ compared with the control group. Sham: sham group; control: control group; paeonol: paeonol group. 

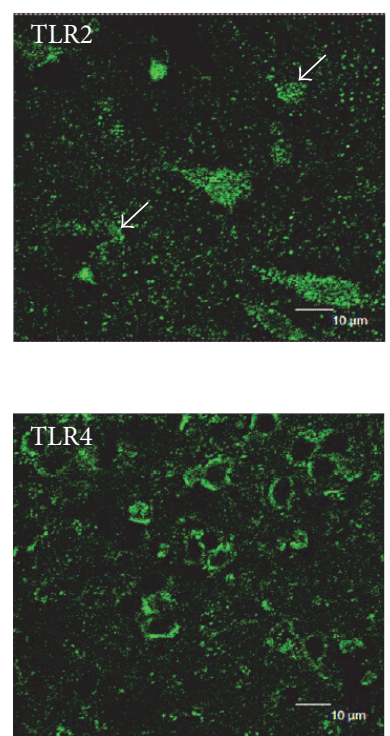
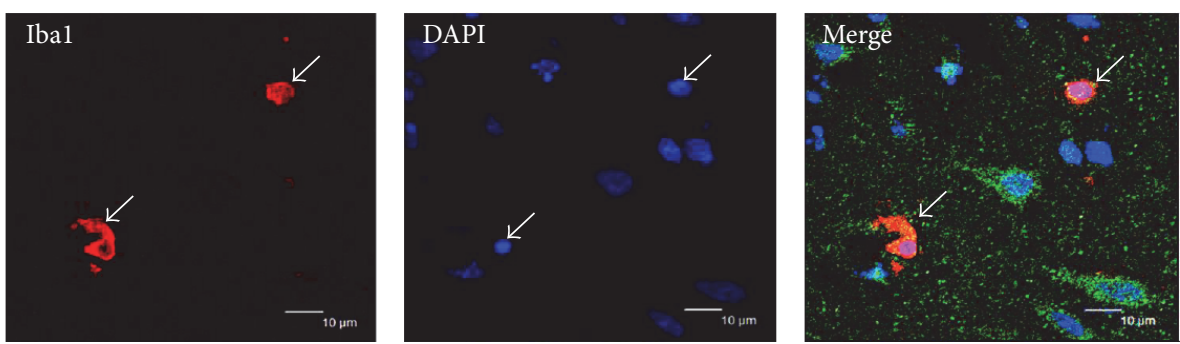

(a)

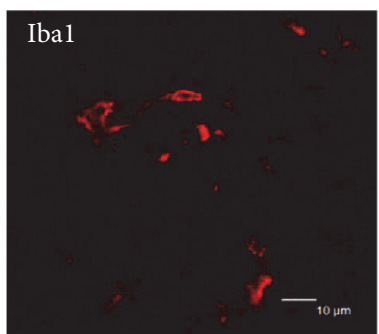

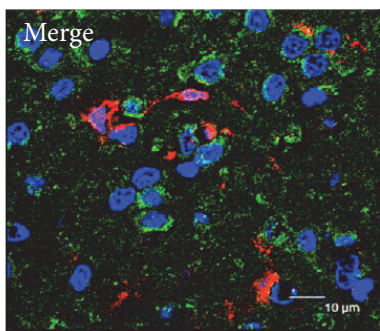

(b)

FIGURE 7: Effect of paeonol on double immunofluorescence analysis in cerebral ischemia-reperfusion injured rats. (a) Double immunofluorescence analysis revealed the colocalization of TLR2-immunoreactive cells (green) with the microglia marker Ibal (red, colocalization marked with white arrows); (b) no colocalization of TLR4 (green) with Ibal (red) was observed $(n=2)$. Scale bar $=10 \mu \mathrm{m}$.

the abovementioned studies. By contrast, no colocalization of TLR4 staining with Ibal was observed in the control group. Our findings indicated that the inflammatory responses of microglia within the cortical penumbra may mainly occur through the TLR2 signaling pathway, whereas those in other brain cells, such as astrocytes and neurons, or in other ischemic sites, such as the cortical ischemic core or striatum, may occur through the TLR4 signaling pathway. However, additional studies are required in the future to validate these findings.

Some limitations in the present study because the study used immunochemistry images alone are sometimes not enough to provide quantitative measurements. We will perform to complement these data with immunoblotting or ELISA, in particular, TLR2, TLR4, and NF- $\kappa$ B expression levels in the future.

In conclusion, paeonol pretreatment ameliorated cerebral infarction and neurological deficits, probably by reducing many proinflammatory receptors and mediators in cerebral ischemia-reperfusion injured rats, although the mechanisms are not clear.

\section{Competing Interests}

The authors wish to confirm that there is no known conflict of interests associated with this publication and there has been no significant financial support for this work that could have influenced its outcome.

\section{Acknowledgments}

This study was supported by a grant from China Medical University (CMU103-S-45), by a grant from Chinese Medicine Research Center, China Medical University (Ministry of
Education, The Aim for the Top University Plan), and, in part, by the Taiwan Ministry of Health and Welfare Clinical Trial and Research Center of Excellence (MOHW105-TDU-B-212133019). The authors also thank Hsiao-Yun $\mathrm{Pu}, \mathrm{Chia}-\mathrm{H}$ sin Pan, Sin-Yi Luo, and Ning-Yi Du for technical assistance.

\section{References}

[1] T. Shichita, T. Ago, M. Kamouchi, T. Kitazono, A. Yoshimura, and H. Ooboshi, "Novel therapeutic strategies targeting innate immune responses and early inflammation after stroke," Journal of Neurochemistry, vol. 123, no. 2, pp. 29-38, 2012.

[2] T. M. Woodruff, J. Thundyil, S.-C. Tang, C. G. Sobey, S. M. Taylor, and T. V. Arumugam, "Pathophysiology, treatment, and animal and cellular models of human ischemic stroke," Molecular Neurodegeneration, vol. 6, no. 1, article no. 11, 2011.

[3] E. C. Jauch, J. L. Saver, H. P. Adams et al., "Guidelines for the early management of patients with acute ischemic stroke," Stroke, vol. 44, no. 3, pp. 870-947, 2013.

[4] T. Shichita, R. Sakaguchi, M. Suzuki, and A. Yoshimura, "Postischemic inflammation in the brain," Frontiers in Immunology, vol. 3, article 00132, 2012.

[5] M. E. Sughrue, A. Mehra, E. S. Connolly Jr., and A. L. D'Ambrosio, "Anti-adhesion molecule strategies as potential neuroprotective agents in cerebral ischemia: a critical review of the literature," Inflammation Research, vol. 53, no. 10, pp. 497508, 2004.

[6] Á. Chamorro, A. Meisel, A. M. Planas, X. Urra, D. van de Beek, and R. Veltkamp, "The immunology of acute stroke," Nature Reviews Neurology, vol. 8, no. 7, pp. 401-410, 2012.

[7] L. Garcia-Bonilla, C. Benakis, J. Moore, C. Iadecola, and J. Anrather, "Immune mechanisms in cerebral ischemic tolerance," in Brain-Immune Interactions in Health and Disease, p. 16, Frontiers in Endocrinology, 2014. 
[8] Y. Kong and Y. Le, "Toll-like receptors in inflammation of the central nervous system," International Immunopharmacology, vol. 11, no. 10, pp. 1407-1414, 2011.

[9] K. B. Vartanian and M. P. Stenzel-Poore, "Toll-Like receptor tolerance as a mechanism for neuroprotection," Translational Stroke Research, vol. 1, no. 4, pp. 252-260, 2010.

[10] Y. Wang, P. Ge, and Y. Zhu, "TLR2 and TLR4 in the brain injury caused by cerebral ischemia and reperfusion," Mediators of Inflammation, vol. 2013, Article ID 124614, 8 pages, 2013.

[11] E. Okun, K. J. Griffioen, and M. P. Mattson, "Toll-like receptor signaling in neural plasticity and disease," Trends in Neurosciences, vol. 34, no. 5, pp. 269-281, 2011.

[12] D. Brea, M. Blanco, P. Ramos-Cabrer et al., "Toll-like receptors 2 and 4 in ischemic stroke: outcome and therapeutic values," Journal of Cerebral Blood Flow and Metabolism, vol. 31, no. 6, pp. 1424-1431, 2011.

[13] S. Ferronato, M. G. Lira, S. Olivato et al., "Upregulated expression of toll-like receptor 4 in peripheral blood of ischaemic stroke patients correlates with cyclooxygenase 2 expression," European Journal of Vascular and Endovascular Surgery, vol. 41, no. 3, pp. 358-363, 2011.

[14] S.-C. Chun, S. Y. Jee, S. G. Lee, S. J. Park, J. R. Lee, and S. C. Kim, "Anti-inflammatory activity of the methanol extract of Moutan Cortex in LPS-activated Raw264.7 cells," EvidenceBased Complementary and Alternative Medicine, vol. 4, no. 3, pp. 327-333, 2007.

[15] P.-K. Fu, C.-Y. Yang, T.-H. Tsai, and C.-L. Hsieh, "Moutan cortex radicis improves lipopolysaccharide-induced acute lung injury in rats through anti-inflammation," Phytomedicine, vol. 19, no. 13, pp. 1206-1215, 2012.

[16] S. Rho, H.-S. Chung, M. Kang et al., "Inhibition of production of reactive oxygen species and gene expression profile by treatment of ethanol extract of Moutan Cortex Radicis in oxidative stressed PC12 cells," Biological and Pharmaceutical Bulletin, vol. 28, no. 4, pp. 661-666, 2005.

[17] C.-L. Hsieh, C.-Y. Cheng, T.-H. Tsai et al., "Paeonol reduced cerebral infarction involving the superoxide anion and microglia activation in ischemia-reperfusion injured rats," Journal of Ethnopharmacology, vol. 106, no. 2, pp. 208-215, 2006.

[18] C.-Y. Cheng, S.-Y. Su, N.-Y. Tang, T.-Y. Ho, S.-Y. Chiang, and C.L. Hsieh, "Ferulic acid provides neuroprotection against oxidative stress-related apoptosis after cerebral ischemia/reperfusion injury by inhibiting ICAM-1 mRNA expression in rats," Brain Research, vol. 1209, pp. 136-150, 2008.

[19] J. Chen, P. R. Sanberg, Y. Li et al., "Intravenous administration of human umbilical cord blood reduces behavioral deficits after stroke in rats," Stroke, vol. 32, no. 11, pp. 2682-2688, 2001.

[20] R. Jin, L. Liu, S. Zhang, A. Nanda, and G. Li, "Role of inflammation and its mediators in acute ischemic stroke," Journal of Cardiovascular Translational Research, vol. 6, no. 5, pp. 834-851, 2013.

[21] C. Iadecola and J. Anrather, "The immunology of stroke: from mechanisms to translation," Nature Medicine, vol. 17, no. 7, pp. 796-808, 2011.

[22] A. Y. Lai and K. G. Todd, "Microglia in cerebral ischemia: molecular actions and interactions This is paper is one of a selection of papers published in this Special Issue, entitled Young Investigator's Forum," Canadian Journal of Physiology and Pharmacology, vol. 84, no. 1, pp. 49-59, 2006.

[23] S.-C. Tang, T. V. Arumugam, X. Xu et al., "Pivotal role for neuronal Toll-like receptors in ischemic brain injury and functional deficits," Proceedings of the National Academy of Sciences of the United States of America, vol. 104, no. 34, pp. 13798-13803, 2007.

[24] W. Barakat, N. Safwet, N. N. El-Maraghy, and M. N. M. Zakaria, "Candesartan and glycyrrhizin ameliorate ischemic brain damage through downregulation of the TLR signaling cascade," European Journal of Pharmacology, vol. 724, no. 1, pp. 43-50, 2014.

[25] K. Hyakkoku, J. Hamanaka, K. Tsuruma et al., "Toll-like receptor 4 (TLR4), but not TLR3 or TLR9, knock-out mice have neuroprotective effects against focal cerebral ischemia," Neuroscience, vol. 171, no. 1, pp. 258-267, 2010.

[26] X.-K. Tu, W.-Z. Yang, S.-S. Shi et al., "Baicalin inhibits TLR2/4 signaling pathway in rat brain following permanent cerebral ischemia," Inflammation, vol. 34, no. 5, pp. 463-470, 2011.

[27] L. Zhang, M. Chopp, X. Liu et al., "Combination therapy with VELCADE and tissue plasminogen activator is neuroprotective in aged rats after stroke and targets MicroRNA-146a and the toll-like receptor signaling pathway," Arteriosclerosis, Thrombosis, and Vascular Biology, vol. 32, no. 8, pp. 1856-1864, 2012.

[28] G. Ziegler, D. Harhausen, C. Schepers et al., "TLR2 has a detrimental role in mouse transient focal cerebral ischemia," Biochemical and Biophysical Research Communications, vol. 359, no. 3, pp. 574-579, 2007.

[29] G. W. Kreutzberg, "Microglia: a sensor for pathological events in the CNS," Trends in Neurosciences, vol. 19, no. 8, pp. 312-318, 1996.

[30] W. Eric Thomas, "Brain macrophages: evaluation of microglia and their functions," Brain Research Reviews, vol. 17, no. 1, pp. 61-74, 1992.

[31] H. Boutin, R. A. LeFeuvre, R. Horai, M. Asano, Y. Iwakura, and N. J. Rothwell, "Role of IL- $1 \alpha$ and IL- $1 \beta$ in ischemic brain damage," The Journal of Neuroscience, vol. 21, no. 15, pp. 55285534, 2001.

[32] Y. Yamasaki, N. Matsuura, H. Shozuhara et al., "Interleukin-1 as a pathogenetic mediator of ischemic brain damage in rats," Stroke, vol. 26, no. 4, pp. 676-681, 1995.

[33] S. M. Allan, P. J. Tyrrell, and N. J. Rothwell, "Interleukin-1 and neuronal injury," Nature Reviews Immunology, vol. 5, no. 8, pp. 629-640, 2005.

[34] D. P. Abulafia, J. P. De Rivero Vaccari, J. D. Lozano, G. Lotocki, R. W. Keane, and W. D. Dietrich, "Inhibition of the inflammasome complex reduces the inflammatory response after thromboembolic stroke in mice," Journal of Cerebral Blood Flow and Metabolism, vol. 29, no. 3, pp. 534-544, 2009.

[35] T. Liu, R. K. Clark, P. C. McDonnell et al., "Tumor necrosis factor- $\alpha$ expression in ischemic neurons," Stroke, vol. 25 , no. 7 , pp. 1481-1488, 1994.

[36] Y. Murakami, K. Saito, A. Hara et al., "Increases in tumor necrosis factor- $\alpha$ following transient global cerebral ischemia do not contribute to neuron death in mouse hippocampus," Journal of Neurochemistry, vol. 93, no. 6, pp. 1616-1622, 2005.

[37] H. Offner, S. Subramanian, S. M. Parker, M. E. Afentoulis, A. A. Vandenbark, and P. D. Hurn, "Experimental stroke induces massive, rapid activation of the peripheral immune system," Journal of Cerebral Blood Flow and Metabolism, vol. 26, no. 5, pp. 654-665, 2006.

[38] I. Ginis, R. Jaiswal, D. Klimanis, J. Liu, J. Greenspon, and J. M. Hallenbeck, "TNF- $\alpha$-induced tolerance to ischemic injury involves differential control of NF- $\kappa$ B transactivation: the role of NF- $\kappa$ B association with p300 adaptor," Journal of Cerebral Blood Flow and Metabolism, vol. 22, no. 2, pp. 142-152, 2002. 
[39] M. E. Meistrell III, G. I. Botchkina, H. Wang et al., "Tumor necrosis factor is a brain damaging cytokine in cerebral ischemia," Shock, vol. 8, no. 5, pp. 341-348, 1997.

[40] F. C. Barone, B. Arvin, R. F. White et al., "Tumor necrosis factor$\alpha$ : a mediator of focal ischemic brain injury," Stroke, vol. 28, no. 6, pp. 1233-1244, 1997.

[41] J. M. Hallenbeck, "The many faces of tumor necrosis factor in stroke," Nature Medicine, vol. 8, no. 12, pp. 1363-1368, 2002.

[42] S. Lehnardt, S. Lehmann, D. Kaul et al., "Toll-like receptor 2 mediates CNS injury in focal cerebral ischemia," Journal of Neuroimmunology, vol. 190, no. 1-2, pp. 28-33, 2007.

[43] J. R. Caso, J. M. Pradillo, O. Hurtado, P. Lorenzo, M. A. Moro, and I. Lizasoain, "Toll-like receptor 4 is involved in brain damage and inflammation after experimental stroke," Circulation, vol. 115, no. 12, pp. 1599-1608, 2007. 


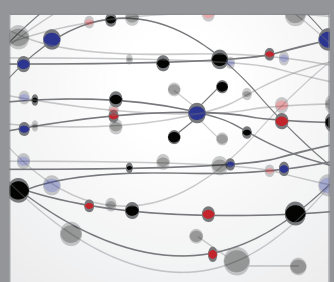

The Scientific World Journal
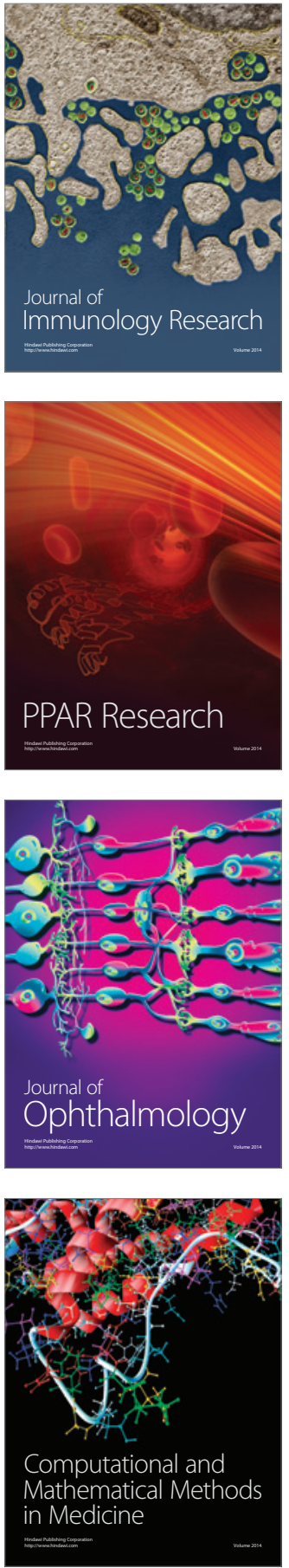

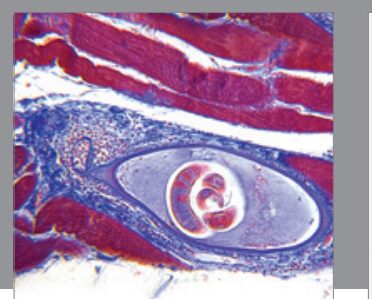

Gastroenterology Research and Practice

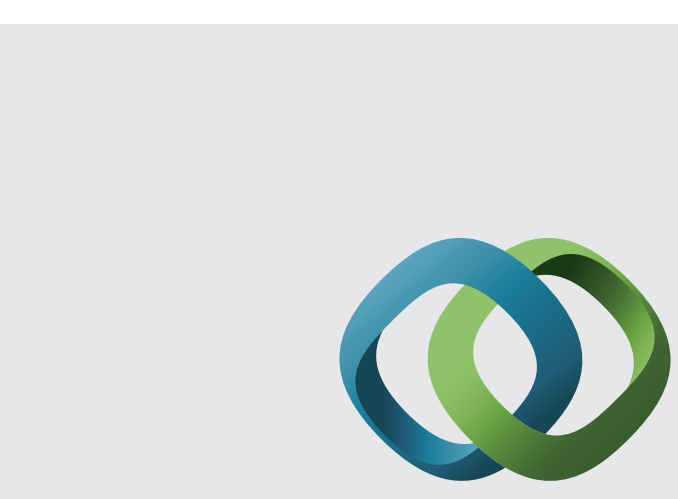

\section{Hindawi}

Submit your manuscripts at

http://www.hindawi.com
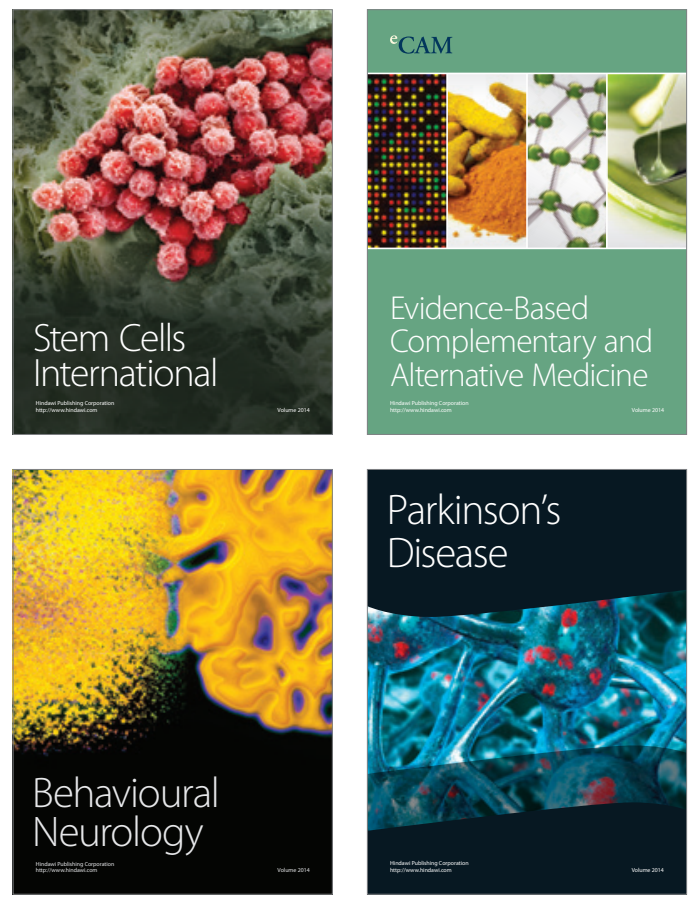
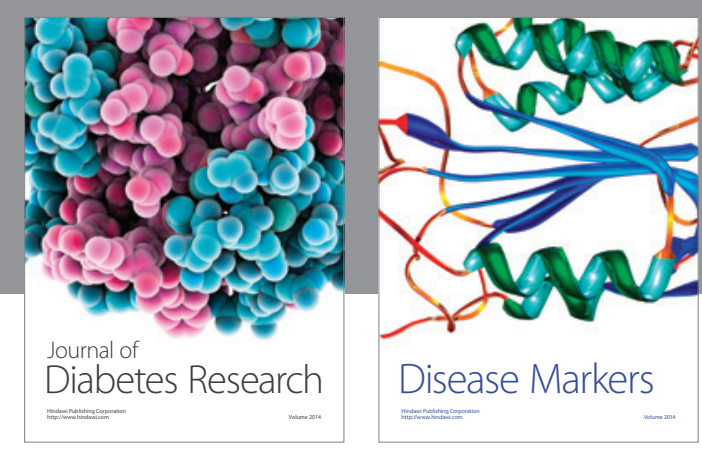

Disease Markers
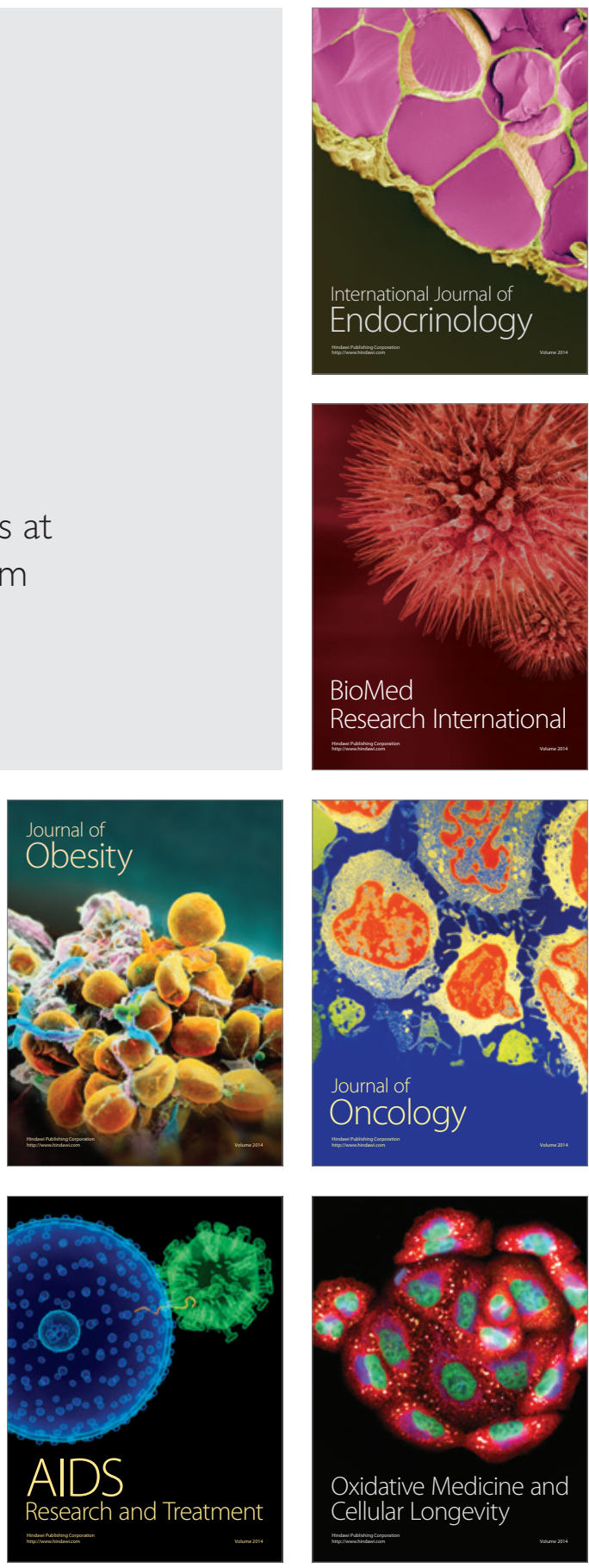